ISSN: 2277-3754

ISO 9001:2008 Certified

International Journal of Engineering and Innovative Technology (IJEIT)

Volume 10, Issue 4, October 2020

\title{
Design and 3d-printing of a body-powered prosthetic limb for amputee
}

\author{
Iwuoha, A. U.and Iheme, C. O. \\ ${ }^{1}$ Department of Mechanical Engineering, Imo State University, Owerri, Nigeria.
}

\begin{abstract}
D Printing is a new digital model-driven process for the printing of $3 D$ objects layer by layer. $3 D$ printing is an innovative technology. Today, it is widely used in many areas and provides alternative production methods including dimensional precision and the ability to print complex forms from many different textiles. $3 D$ printing is a novel medical application with a wide variety of possible applications, such as the printing of organic tissue, custom implants and orthopedic equipment. This work used the $3 D$ printing technology and produced a body-powered prosthetic limb for a 12-year old amputee boy. The prosthetic design for the limb was made to be parametrically scalable, to appropriately size the identified wearer. The design was done using Fusion 360 software, converted to Stereo lithography (STL) format with Maker-Bot software and then 3D-printed with Maker-Bot 3D printing machine. The material used was a flexible filament thermoplastic polyurethane. The prosthetic limb is bodypowered. It is activated to fold the fingers to achieve a grip by moving the residual limb to which it is attached. Easing the tension on the residual limb re-opens the fingers. A sliding curved joint, the relation of the moving (fingers) and the fixed part (palm) is the best choice, as it is easy to print and close to the hand of the human being. The 3D-printed prosthetic limb was evaluated according to its set requirements. It weighs 188 $\mathrm{g}$ (met the target of less than $200 \mathrm{~g}$ ). On wearing the limb on the amputee boy, the interfacing wear-in socket was comfortable and stable on the boy. There were no painful pressures on the bands around the residual limb. The palm was able to change quickly from closed state to open state. Overall, the demonstrations on the amputee boy showed the usability of the limb. In comparison with the conventional limbs for similar amputee, the results obtained with the use of this prosthetic limb indicate better functionality, flexibility and convenience on the user. The main problem of this prosthetic limb is the ability to control each finger independently. Achievement of this requires further works in this area, particularly in association with bionic hand prosthetics which requires additional set of technologies.
\end{abstract}

Key Words: Prosthetic design, Prosthetic limb, 3D printing, Amputee, Body-powered.

\section{INTRODUCTION}

Over the years, people especially children suffer from amputated limbs either from birth (congenial), or as a result of childhood accidents which result in amputation. They suffer growing up with the trauma of having to use one arm to do virtually everything; while the amputated arm does little or nothing depending on the condition. Some adults today suffer paralytic disorders as a result of fatal accidents or some other related issues.

Manuscript received: 25 September 2020

Manuscript received in revised form: 25 October 2020

Manuscript accepted: 09 November 2020

Manuscript Available online: 15 November 2020
The traditional prosthetic limb offered by orthopedic hospitals has a very high cost. Additive manufacturing method and particularly 3Dprinting version can offer a highly affordable and flexible alternative way of providing functional prosthetic limb.

$3 \mathrm{D}$ printing is a new technology that uses a digital model for the layer-by-layer printing of a tridimensional material. The latest in $3 \mathrm{D}$ printing in the healthcare industry is new to many future uses, such as organic tissue printing or custom implants and orthopedic devices. This technique is used extensively in many fields and offers a personalized manufacture process with the advantages of dimensional accuracy and the ability to print complex shapes from a variety of materials. The prospect of reducing the cost of materials and manufacturing time has recently attracted a great amount of interest from 3D printed prostheses. Looking at the use of prosthetics in a broader picture, the distribution worldwide is unequal. Many prosthetic devices, while not readily available to all, are highly developed with technological features. The need for low cost and easily made artificial limbs is strong in developing nations, which is one of the reasons for these solutions [6]. This refers to amputated children who develop quickly and need to upgrade their prosthesis devices quickly as the years. [5].

Unmitigated limb disabilities render most people function in limited sense with attendant economic / social incidence. With the present state of medical progress made possible by medical knowledge and engineering technology, people feel awkward with limb disabilities and this is particularly felt in developing countries where very limited material and human resources make obtainment of these services difficult or near impossible. The odds associated with their movements coupled with superstitious tendencies of these societies make their full integration and psychological acceptance in the wider society a begging issue.

Thanks to the advanced level of medical knowledge and technologies in western countries; amputation is rarely performed, while in developing countries, it is a practice that is the norm. The increased levels of activities (work, mobility, play) and the surge in human population of developing countries have increased the number of incidents with limb related disabilities. The low knowledge level and narrow experience of the resident medical personnel have not provided the required enabling assistance. Violence, diabetes, polio and the diffuse presence of landmines are considered to be the 
ISSN: 2277-3754

\section{ISO 9001:2008 Certified}

International Journal of Engineering and Innovative Technology (IJEIT)

Volume 10, Issue 4, October 2020

most common causes of limb damage which eventually lead to amputations in developing countries [6].

In developing countries, the majority of the prostheses available are second and prostheses provided by amputee NGOs in the developed world. These prostheses split quickly. Different studies have shown that the amputees had been continuously complained about mechanical problems and high repair costs up to half of the used prostheses had to be remedied or changed. The socket, which is not customized, is another problem with secondhand prosthesis. This causes considerable discomfort, pain and injury in some cases. [6]

\section{A. Examination of Amputee}

\section{METHODOLOGY}

An amputee at an orphanage home in Nigeria was identified. The patient was a 12 years old boy with a congenital radial amputation. Visits to the orphanage home for the process of designing a 3D printable prosthetic limb for the child was made in two days. Parametric measurements were taken on these days to enable the design (model) of the prosthetic limb, based on the features of the patient in terms of fit and appearance. The measurements obtained during the examination of the amputee boy are shown in Figure 1.

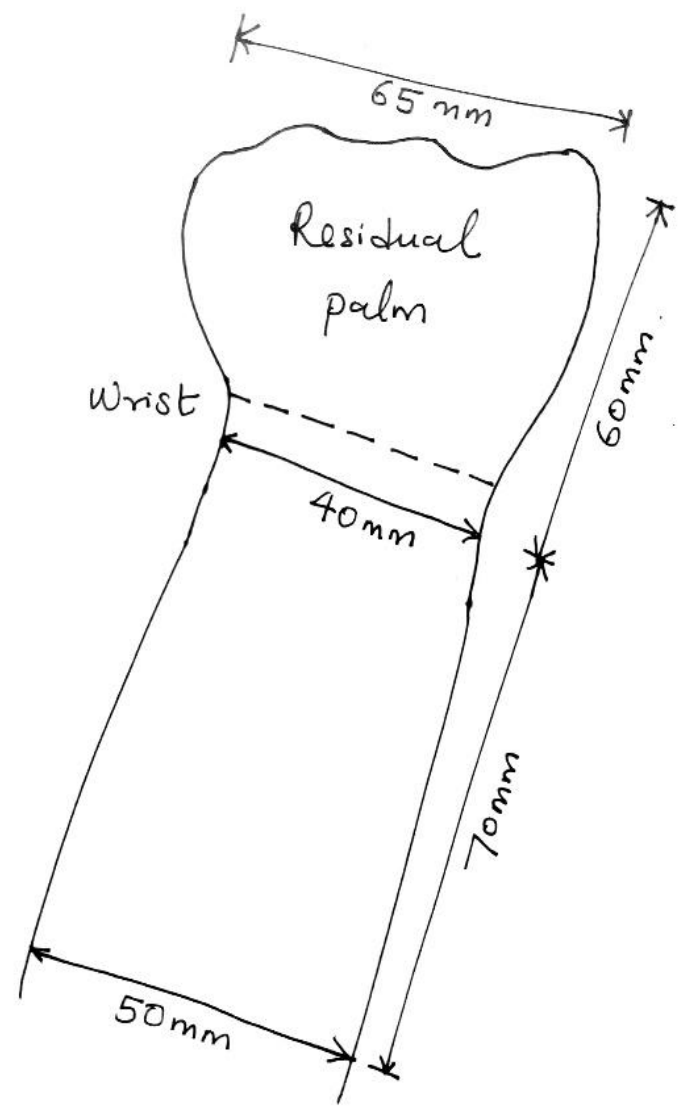

Fig 1.Sketch obtained from examination of the amputee boy. At the end of the examinations / interviews of the patient, the following requirements were set for the prosthesis [1]:
Comfort and Stability: When worn by the boy, the interfacing wear-in socket should be comfortable and stable on the boy. There should be no painful pressures on the bands around the residual limb.

Voluntary Closing of the Fingers: This feature allows the grip force to be modified. When relaxed, elastic joints of your fingers hold your hand open. The elbow's bend closes the hand by drawing on a wire.

Size Adjustability: Until printing, the 3D digital model can be scaled to accommodate various amputees. The whole limb is scalable to various sizes. The individual pieces are not scaled individually for convenience.

Lightweight: The prosthesis should not be heavier than the human version it should replace. When creating the limb, the goal is to make the mass as low as possible. The limb will not weigh more than $200 \mathrm{~g}$ (Target: less than $200 \mathrm{~g}$ ). The prosthesis will be printed with a lowdensity material and all parts except the fingers should be hollow. There will be no electrical attachments -hence body-powered.

Different Grasp Modes: In several different cases, the user has the flexibility of many grip modes to use the prosthesis. The intensity can be changed such that the hand stays closed more or less. Different grip modes can be accomplished in conjunction with the ability to switch thumb.

Quick Motion Ability: The ability to quickly change between closed and open hand will increase the performance of the prosthesis in several situations. The joints will be made of flexible material that can enable it quickly go back to its original position.

Friction on Tip of Finger to Improve Grip: To maintain better grip and reduce the amount of force required when grasping an object, the surface of every fingertip would have added friction. Every fingertip will have extra part, printed in a more flexible material. This will increase the friction on these surfaces.

Locking Mechanism for Closed Grip: The ability to lock a closed location of the prosthesis would minimize the need for an object to be kept in constant strength. The wire may be locked using the other hand when the fingers in the prosthetic are flexed.

The prosthesis limb has been 3D modeled on the residual limb of the amputee boy and has been designed for the purposes of user testing. Before the digital design, it was analyzed for a clear understanding of the size and function of the different parts and their linkage patterns that were obtained after analyzing the amputations sustained by the boy.

\section{B. 2D and 3D Modeling (Design)}

There are 64 bones in the ordinary, 10 for the shoulder and arm, 16 for the wrist and 38 for the hand. These bones function as a motor-driven connector mechanism in conjunction with muscles and ligaments. Transcarpal prosthesis consists of three main components: gauntlet, socket and fingertips. The gauntlet and socket is used to 


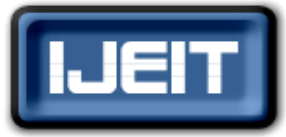

\section{ISSN: 2277-3754 \\ ISO 9001:2008 Certified \\ International Journal of Engineering and Innovative Technology (IJEIT) \\ Volume 10, Issue 4, October 2020}

connect the prosthesis to the user as long as the fingers are captured [6]. During the construction of the prosthetic, the versatility of the extremity was recalled.

The measurements of the sketched arm gave an insight to the parametric design of the prosthetic limb. The prosthetic limb was then modeled with Fusion 360 computer aided design (CAD) software where 2D and 3D models of the design were generated. Fusion 360 is cloud-based CAD software with several different environments integrated, suitable for varied applications. The parametric design made is shown in below Figures.

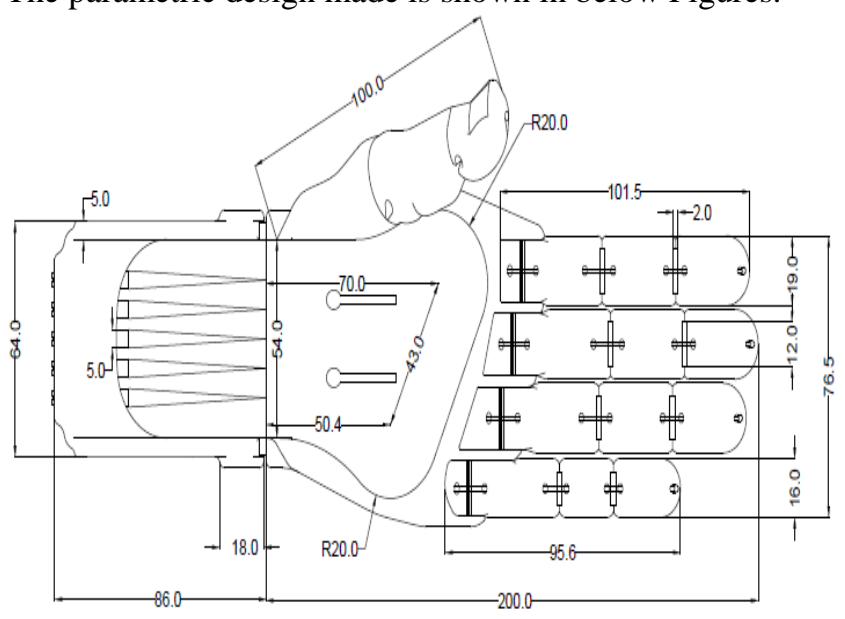

Fig.2. 2D Model of the prosthetic limb for the transcarpal amputation.

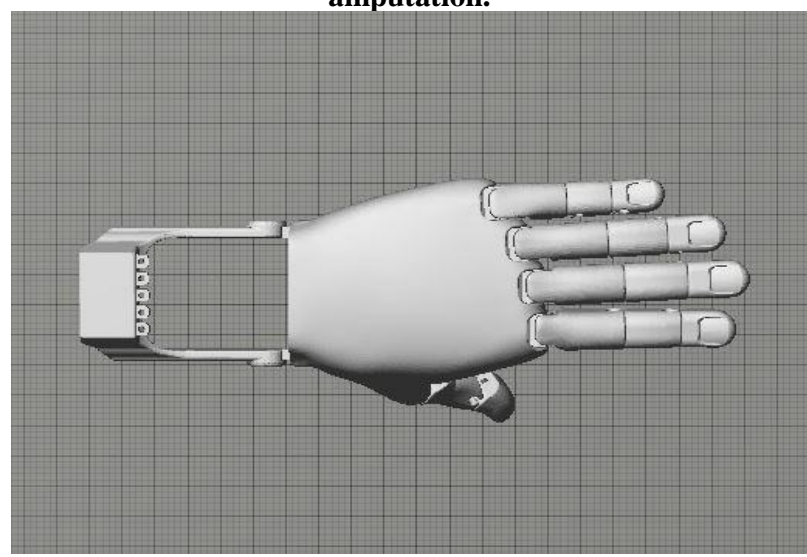

Fig.3.Top view of the 3D model of the prosthetic limb for the transcarpal amputation in Fusion 360 software.

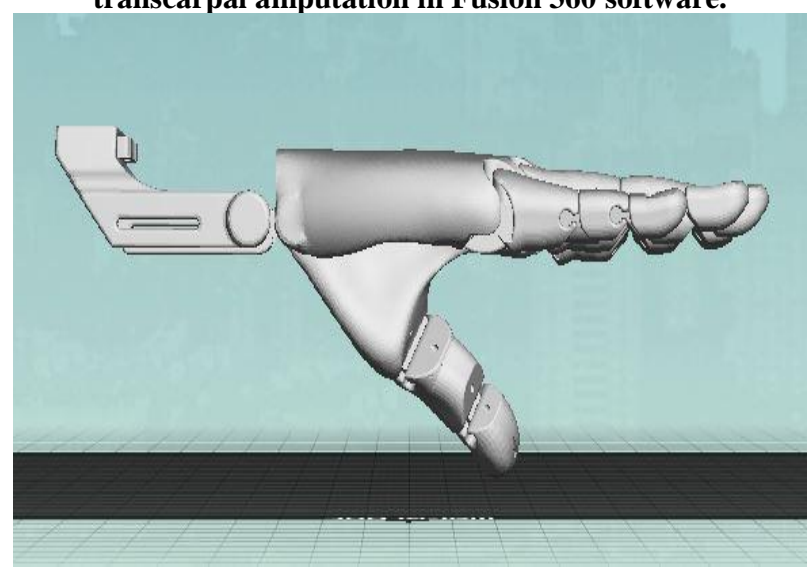

Fig.4. Side view of the 3D model in Fusion 360.

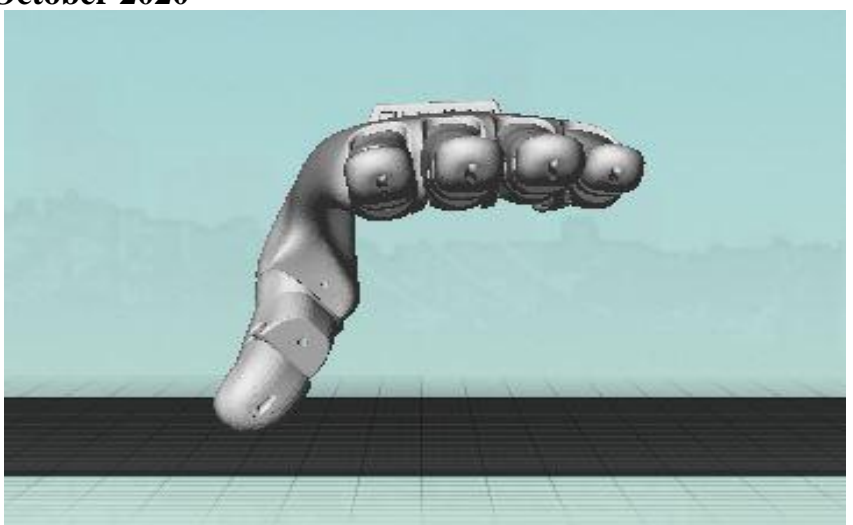

Fig. 5.Front view of the 3D model in Fusion 360.

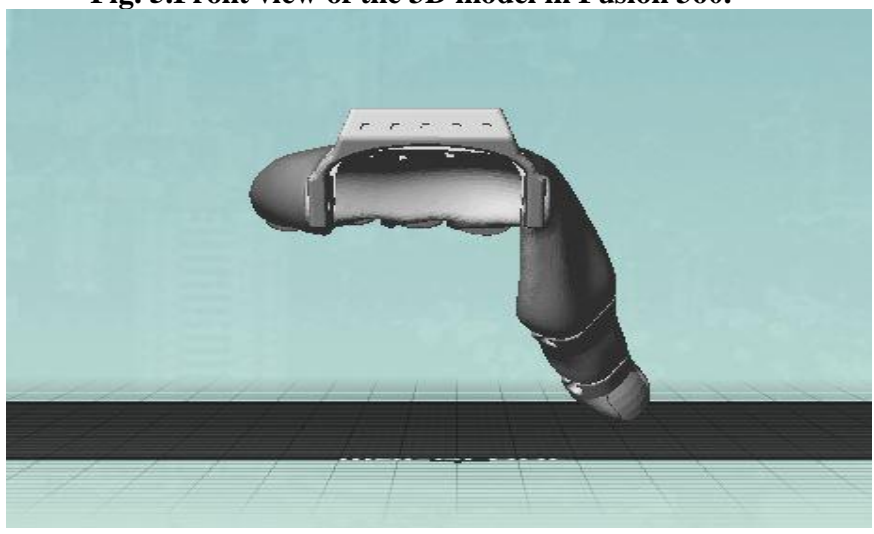

Fig. 6. Back view of the 3D model in Fusion 360 .

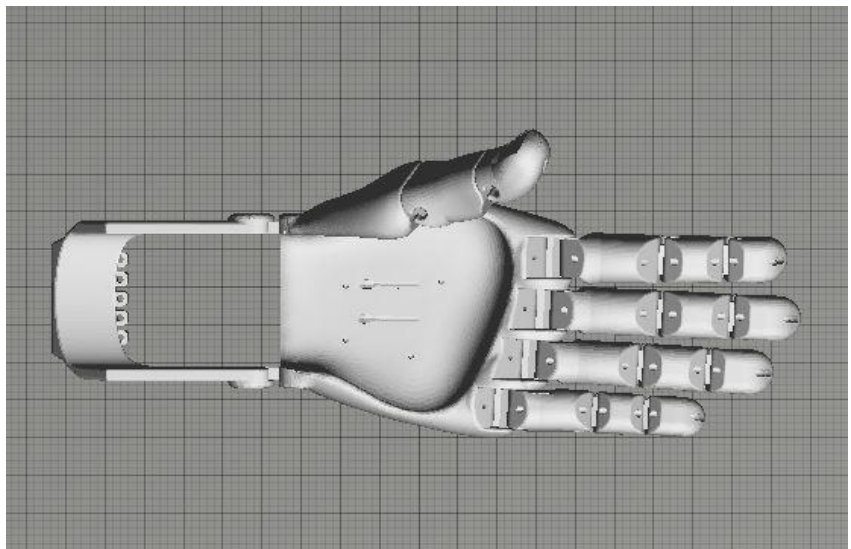

Fig. 7. Bottom view of the 3D model in Fusion 360 .

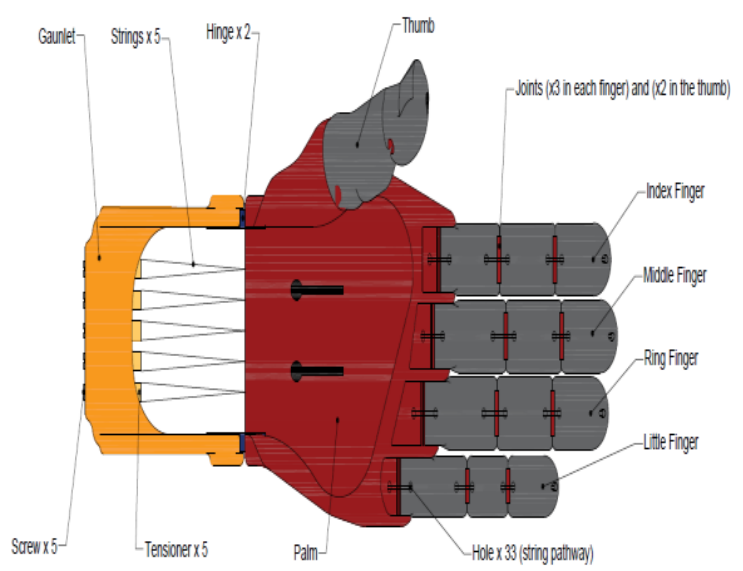

Fig.8.Identification of parts of the prosthetic limb 
ISSN: 2277-3754

\section{ISO 9001:2008 Certified}

International Journal of Engineering and Innovative Technology (IJEIT)

Volume 10, Issue 4, October 2020

\section{MATERIAL SELECTION}

Several materials were put into consideration in terms of physical properties, cost and service efficiency. The material selected for the 3D printing is Thermoplastic Polyurethane (TPU), supplied in rolls of filament.

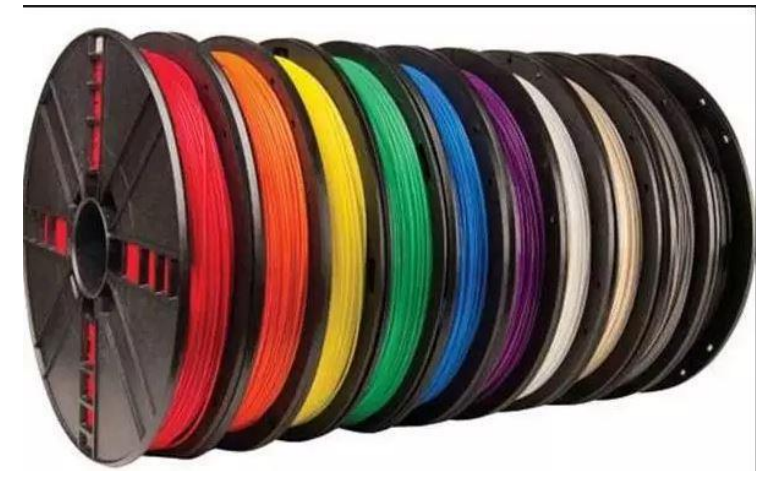

Fig.9. 3D TPU printing filament material (Maker-Bot Type).

TPU is a very common type of elastic polymer or elastomeric filament that can be applied on any correctlyappointed 3D Printer for Fused Deposition Modeling (FDM). The TPU filament is a little more rigid, which makes it easier to extrude. For many kinds of flexible 3D Printer filaments, it is easier to use. It is a highly versatile and resilient media material which is capable of withstanding greater compressive and tensile stresses that are typical to its counterparts: polyactic acid (PLA), butadiene styrene acrylonitrile (ABS) filaments. Table 1 shows the characteristics of the TPU material.

Table 1: Properties of Thermoplastic Polyurethane (TPU)

\begin{tabular}{|c|c|c|}
\hline \multicolumn{3}{|c|}{ Filament } \\
\hline $\mathbf{S} / \mathbf{N}$ & Parameter & Value/Remarks \\
\hline 1 & $\begin{array}{l}\text { Deposition Nozzle } \\
\text { Temperature }\end{array}$ & $210-230^{\circ} \mathrm{C}$ \\
\hline 2 & Bed Temperature & $20-60^{\circ} \mathrm{C}$ \\
\hline 3 & Warping & Minimal \\
\hline 4 & Shrinkage & Minimal \\
\hline 5 & Print Speed & $30 \mathrm{~mm} / \mathrm{s}$ (Average) \\
\hline 6 & Strength & Medium \\
\hline 7 & Flexibility & Very High \\
\hline 8 & Durability & Very High \\
\hline 9 & $\begin{array}{l}\text { Abrasion } \\
\text { Resistance }\end{array}$ & Very High \\
\hline 10 & Soluble & No \\
\hline 11 & Hygroscopic & Yes \\
\hline 12 & Food Safe & Yes \\
\hline 13 & Fumes & Minimal \\
\hline
\end{tabular}

Source: https://all3dp.com/2/tpu-filament-explained-andcompared/

\section{A. 3D Printing of the Prosthetic Limb}

Fused Deposition Modeling (FDM) for 3D printing was the technique used due to its efficiency and compatibility with the selected material. The parameters for the 3D printing were set. Different software's are available for this. Maker-Bot software was used. The parameters set were: bed temperature, deposition nozzle temperature, object alignment, coordinates of the object, layer thickness. The Maker-Bot software generated a 3Dreadable file containing the set parameters; this file in Standard Triangle Language (STL) format, was set or input to the 3D printer. The 3D printer read this file and manufactured the object (prosthetic limb) according to the set dimensions and other parameters. The virtual 3D model was sliced into slim cross-section and created a Standard Triangle Language (STL) file format before the actual nozzle extrusion commenced.

The material was heated and extruded into a construction plane via a screw. The construction fluid travelled constantly down, allowing the object to emerge from one layer to another. A support material was used and extruded, often with a second nozzle, in order to create complex structures with cavities. The excess materials were eliminated by filing off on completion of the printing process.

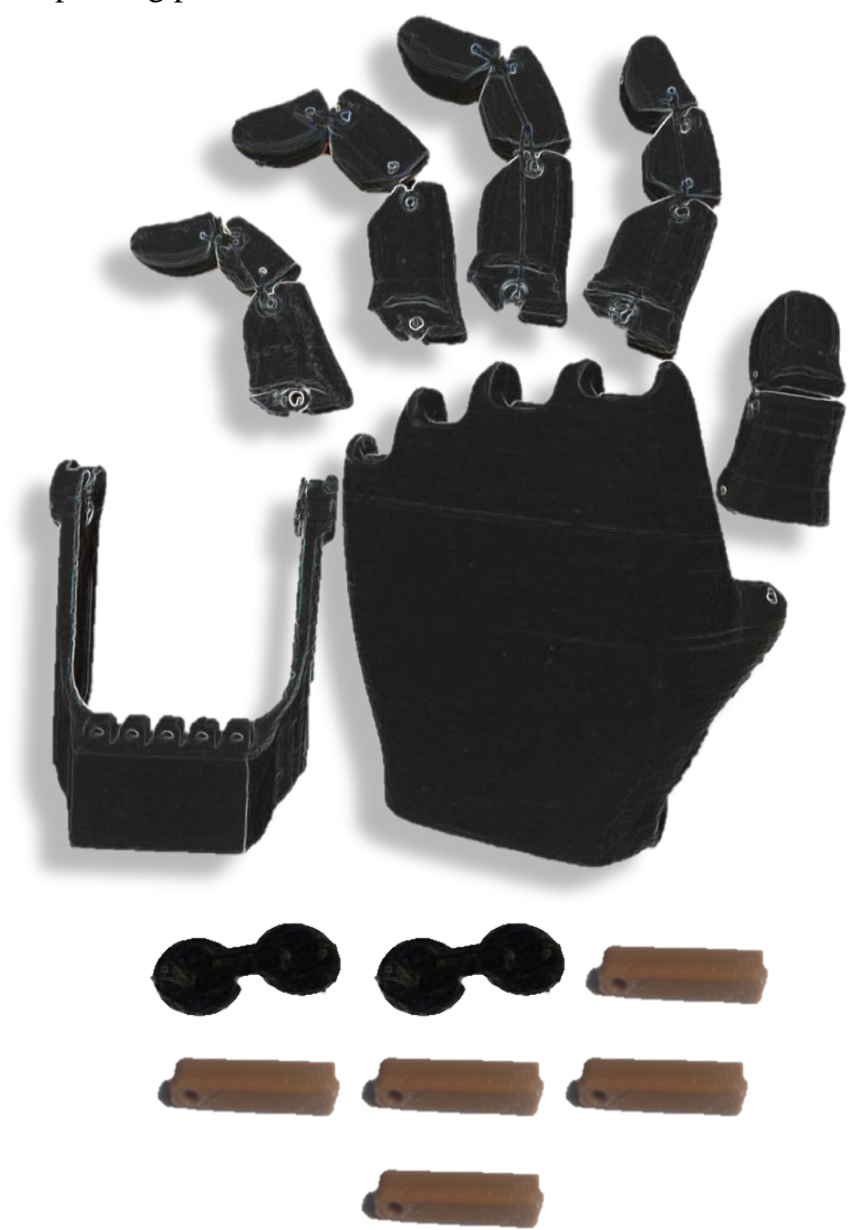

Fig.10.3D-Printed parts (components) of the prosthetic limb. 


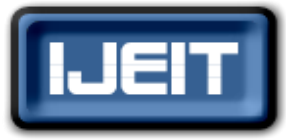

ISSN: 2277-3754

\section{ISO 9001:2008 Certified}

International Journal of Engineering and Innovative Technology (IJEIT)

Volume 10, Issue 4, October 2020

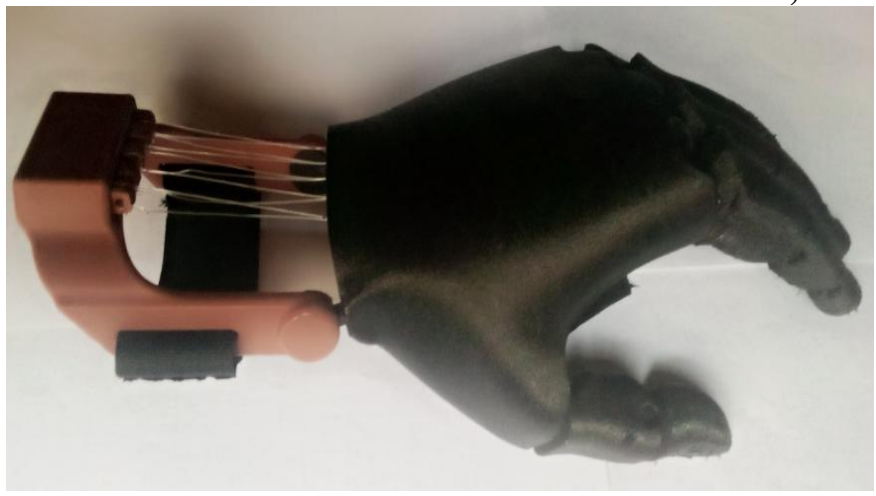

Fig.11.Top view of the 3D-printed prosthetic limb.

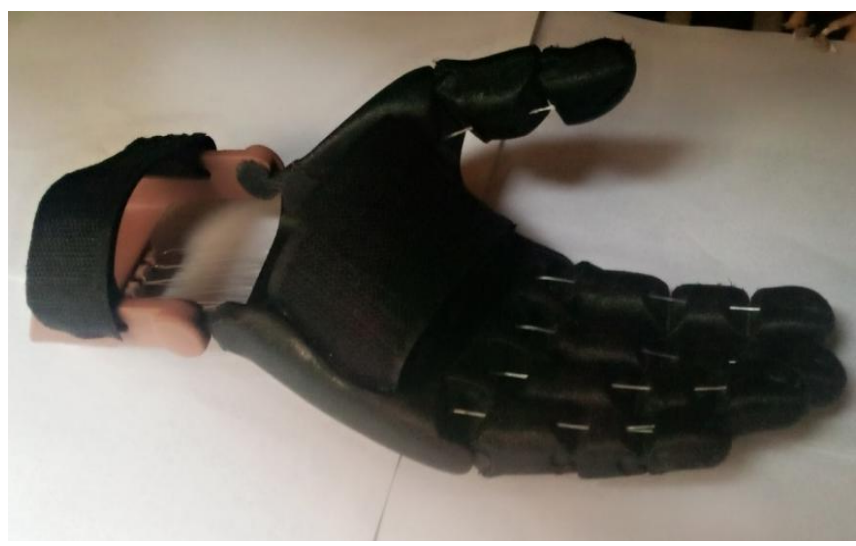

Fig.12.Bottom view of the 3D-printed prosthetic limb.

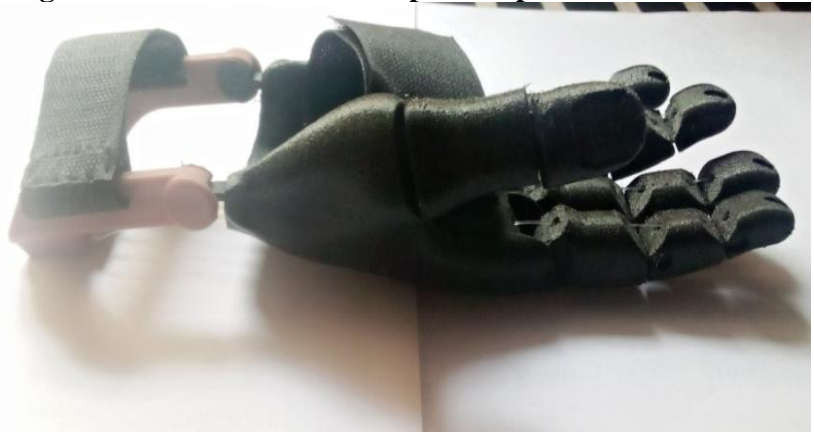

Fig.13.Side view of the 3D-printed prosthetic limb.

\section{RESULTS AND DISCUSSIONS OF DEMONSTRATIONS}

The manufactured (3D-printed) prosthetic limb was evaluated according to its set requirements. Figures 12 to 17 show the amputee boy wearing the prosthetic limb in various grip modes.

\section{A. Grip Mechanisms}

The limb was designed for specific kinds of grip which included power grip and spherical grip as schematically demonstrated in Figure 14. Since the limb is bodypowered, that is, motions of the limb are achieved by exertion/relaxation of tension by the residual limb of the amputee to which it is attached, the fingers are folded by "movement" of the residual limb and easing off of this "movement" re-opens the folded fingers. The relationship between the moving part (fingers) and the fixed part is a curved joint, which is a sliding joint that is considered the best choice because of its ease of 3D printing and resemblance to the human hand. a)

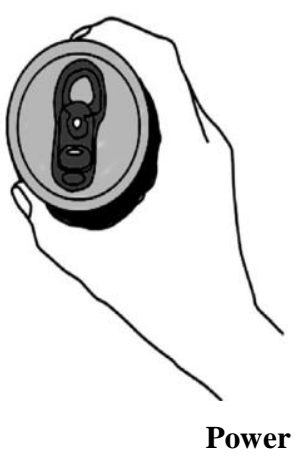

Power b)

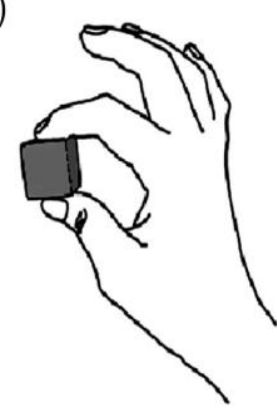

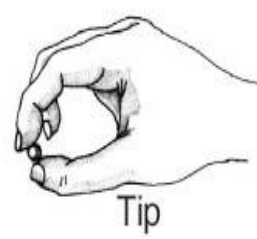

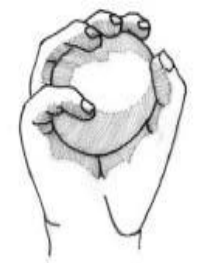

Spherical
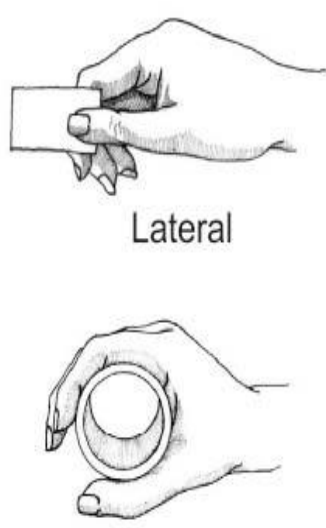

Power
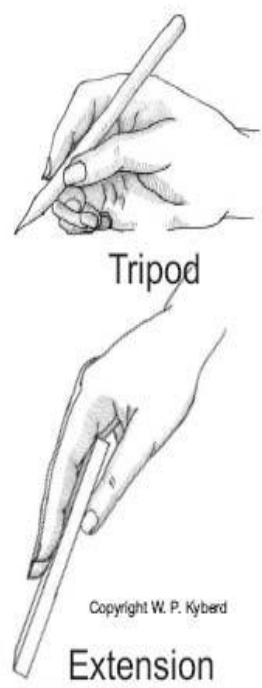

Fig.14.Schematic drawings showing different modes of hand grip.

The prosthetic limb weighs $188 \mathrm{~g}$ (it met the target of less than $200 \mathrm{~g}$ ). On wearing the limb on the amputee boy, it was observed that the interfacing wear-in socket was comfortable and stable on the boy. There were no painful pressures on the bands around the residual limb. The various grip modes schematically shown in Figure 14 were tried out by the amputee boy. Two of the grip modes: power grip and spherical grip are shown demonstrated in Figures.

Elastic joints in the fingers kept the palm open when in relaxed state. When the elbow was flexed together with a pull on a wire, the palm closed. The force can be adjusted to keep the palm in a more or less closed state. Demonstrations proved that the palm was able to change quickly from closed state to open state. This was made possible by the flexible materials that link the joints. The added friction on the fingertips made it possible to maintain better grip and thus reduced the amount of force required on grasping an object. The ability to lock the prosthetic limb (palm) in closed position reduced the need to keep a constant force when holding an object. 


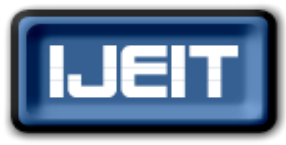

ISSN: 2277-3754

ISO 9001:2008 Certified

International Journal of Engineering and Innovative Technology (IJEIT)

Volume 10, Issue 4, October 2020

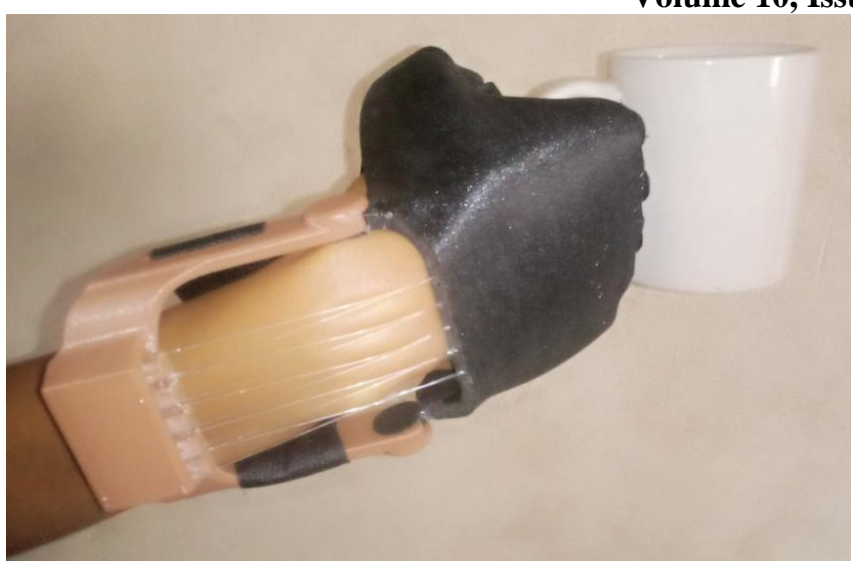

Fig.15. The amputee performing a power grip with the 3D-printed prosthetic limb.

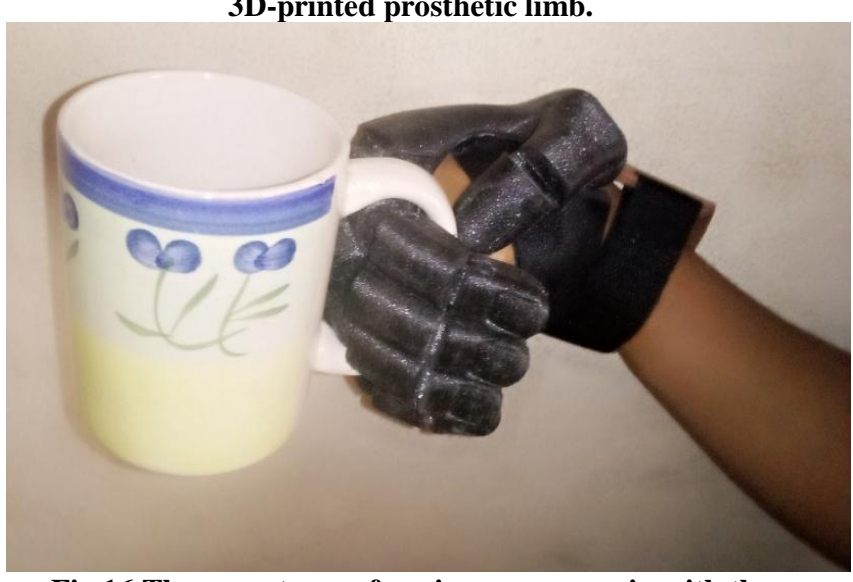

Fig.16.The amputee performing a power grip with the 3D-printed prosthetic limb.

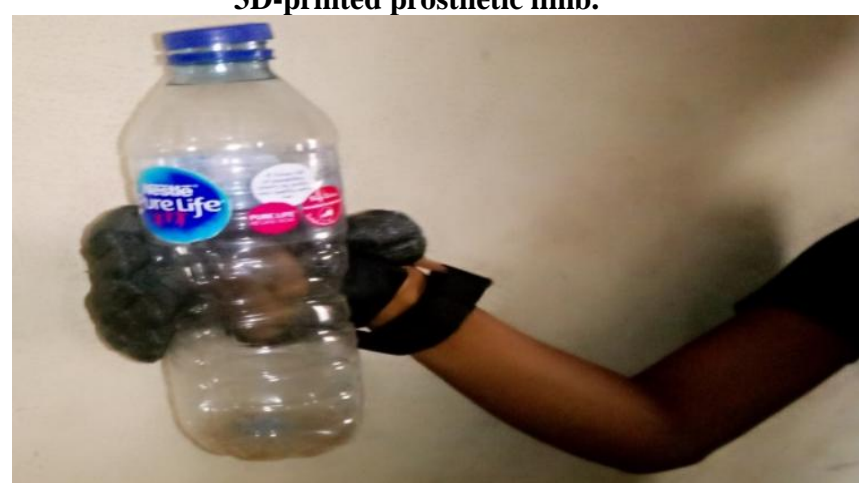

Fig.17.The amputee performing a spherical grip with the 3D-printed prosthetic limb.

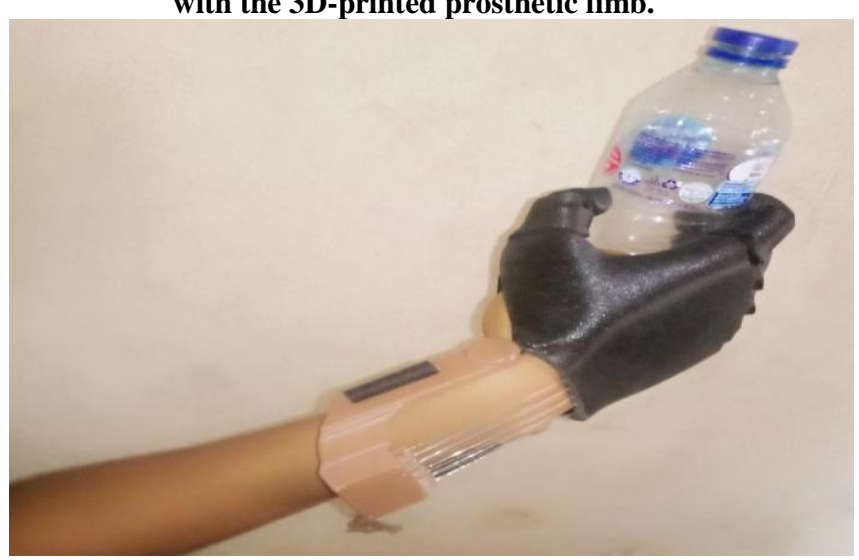

Fig.18.The amputee performing a spherical grip with the 3D-printed prosthetic limb.

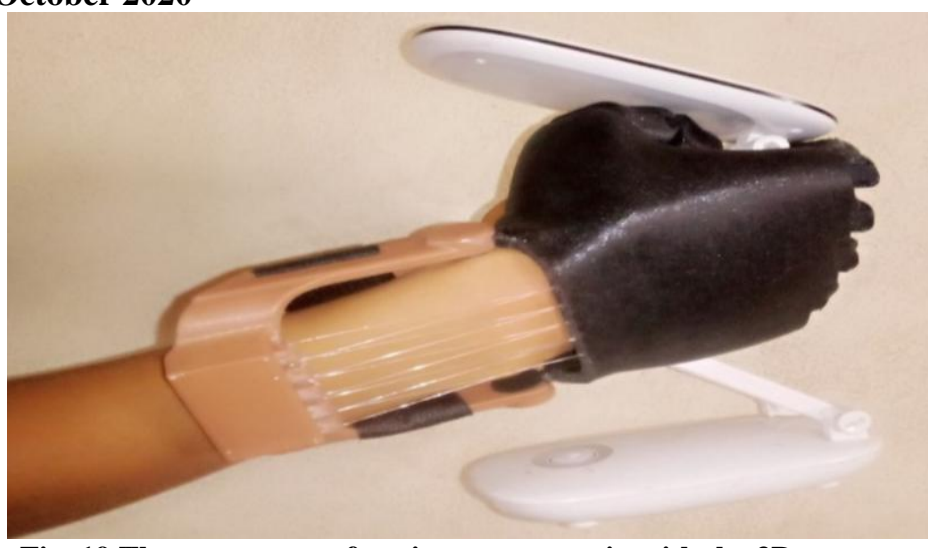

Fig. 19.The amputee performing a power grip with the 3Dprinted prosthetic limb.

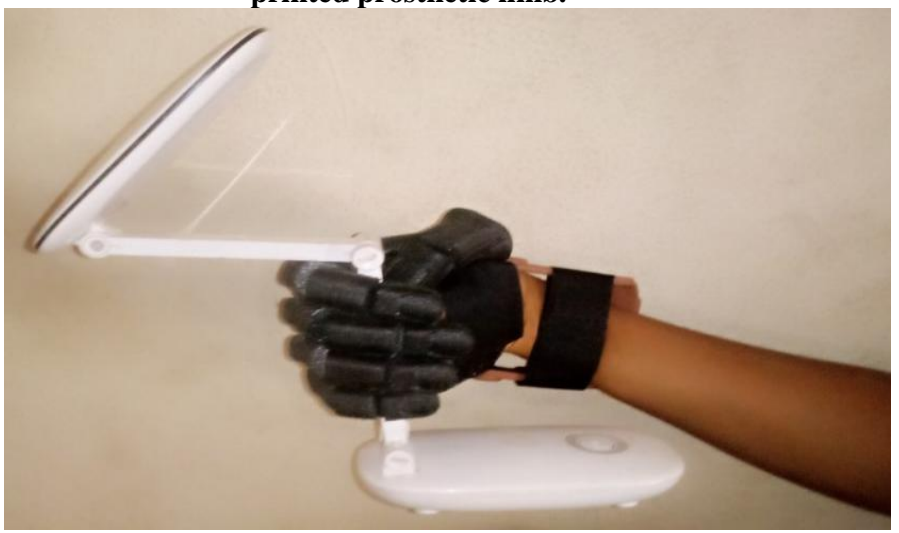

Fig. 20.The 3D-printed prosthetic limb in spherical grip and power grip modes.

\section{CONCLUSION}

This work set out to achieve a functional human bodypowered prosthetic limb for amputee using the 3Dprinting technology. The real-life demonstrations of the $3 \mathrm{D}$-printed limb on the 12 years old amputee boy in an orphanage home showed the usefulness and usability of the limb. In comparison with the conventional limbs for similar amputee, the results obtained with the use of this prosthetic limb indicated better functionality, flexibility and convenience on the user. One of the cases for improvement in this work is the ability to control each finger independently. Further works may be undertaken with the incorporation of bionic hand prosthetic (artificial intelligence powered) [2]. This requires a higher level of technology and may be undertaken in the future.

\section{REFERENCES}

[1] Berning, K., Cohick, S., Johnson, R., Miller, L.A. and Sensinger, J.W., "Comparison of Body Powered Voluntary Opening and Voluntary Closing Prehension for Activities of Daily Life", Journal of Rehabilitation Research \& Development, 51(2), pp: 253-262, 2014.

[2] Fitzgibbons, P. and Medvedev, G., "Functional and Clinical Outcomes of Upper Extremity Amputation", Journal of the American Academy of Orthopedic Surgeons, 23(12), pp: 751-760, 2015.

[3] Gretsch, K.F., Lather, H.D., Peddada, K.V., Deeken, C.R., Wall, L.B. and Goldfarb C.A.,"Development of Novel 3D- 
ISSN: 2277-3754

ISO 9001:2008 Certified

International Journal of Engineering and Innovative Technology (IJEIT)

Volume 10, Issue 4, October 2020

Printed Robotic Prosthetic for Transradial Amputees",

Prosthetic and Orthotic. International (Sage Journal),

Volume 40, Issue 3, pp: 400-403, 2016.

[4] Malin, K. and Matilda, S., (2018),"Creating A Body Powered Prosthetic Arm With 3D Printing Technology". Master's Thesis, Lund University of Biomedical Engineering, pp: 1-75, 2018.

[5] Ortiz-Catalan, M., Hakansson, B. and Brånemark, R.,’An Osseo Integrated Human Machine Gateway for Long Term Sensory Feedback and Motor Control of Artificial Limbs", Science Translational Medicine. Vol. 6, Issue 257, pp: 1-8, 2014.

[6] Sensinger, J.W., Lipsey, J., Thomas, A. and Turner, K., "Design and Evaluation of Voluntary Opening and Voluntary Closing Prosthetic Terminal Device", Journal of Rehabilitation Research \& Development, 52(1), pp: 63-76, 2015. 